$\left(\mathrm{Cl}_{95 \%}\right.$ 0.83-0.98)). Lupus arthritis was more common in risk TT-genotype SLE carriers than in other SLE patients $\left(\chi^{2}=5.902 p=0.015 ; p_{2-t}=0.027\right)$.

We revealed significant increase of CT genotype (RUNX1 rs9979383) in healthy donors vs SLE patients $\left(\chi^{2}=4.14 ; p=0.042 ; \mathrm{dOR}=0.53\left(\mathrm{Cl}_{95 \%} 0.29-0.98\right) ; \mathrm{LR}^{+}\right.$ $\left.=0.69\left(\mathrm{Cl}_{95 \%} 0.45-0.99\right) ; \mathrm{LR}^{-}=1.3\left(\mathrm{Cl}_{95 \%} 1.01-1,56\right)\right)$. Lupus arthritis was more common in SLE CT-genotype carriers than in other SLE patients $\left(\chi^{2}=4.66\right.$ $\mathrm{p}=0.031 ; \mathrm{p}_{2-\mathrm{t}}=0.058$ )

Significant differences in IL6 rs1800795, IL6R rs2228145 and IL6R rs4845618 genotypes distribution between studied groups were not found $\left(\chi^{2}, p=0.427\right.$, $\mathrm{p}=0.559$ and $\mathrm{p}=0.407$, correspondingly) but GG-genotype (IL6 rs1800795) carriership in SLE patients was associated with increased APS frequency $\left(\chi^{2}=4.45\right.$, $\mathrm{p}=0.035 ; \mathrm{dOR}=0.19\left(\mathrm{Cl}_{95 \%}\right.$ 0.04-0.9); $\mathrm{LR}^{+}=0.28\left(\mathrm{Cl}_{95 \%}\right.$ 0.07-0.93); $\mathrm{LR}^{-}=1.41$ $\left(\mathrm{Cl}_{95 \%}\right.$ 1.03-1.64).

Conclusion: Our data suggest the susceptibility to SLE in TT genotype of STAT4 rs7574865 polymorphism, protective role of CT genotype of RUNX1 rs9979383 for SLE and association between GG-genotype of IL6 rs 1800795 and APS in SLE patients in Belarusian population. Lupus arthritis was associated with TT genotype of STAT4 rs7574865 and CT genotype of RUNX1 rs9979383. REFERENCES:

[1] Chen L, Morris DL, Vyse TJ. Genetic advances in systemic lupus erythematosus: an update. Curr Opin Rheumatol 2017;29:423-33.

[2] Hochberg MC. Updating the American College of Rheumatology Revised Criteria for the classification of Systemic Lupus Erythematosus. Arthritis Rheum 1997;40:1725

Disclosure of Interests: None declared

DOI: 10.1136/annrheumdis-2021-eular.2523

\section{AB0010 ASSOCIATION OF SAA1 GENE POLYMORPHISM -13T/C (RS12218) WITH ANKYLOSING SPONDYLITIS IN RUSSIAN POPULATION}

1. Guseva ${ }^{1}$, K. Sakharova ${ }^{2}$, M. Krylov ${ }^{1}$, E. Samarkina ${ }^{1}$, S. Erdes ${ }^{2} .{ }^{1} V . A$.

Nasonova Research Institute of Rheumatology, Laboratory of Immunology and Molecular Biology of Rheumatic Diseases, Moscow, Russian Federation; ${ }^{2}$ V.A. Nasonova Research Institute of Rheumatology, Laboratory of Spondyloarthritis, Moscow, Russian Federation

Background: Ankylosing spondylitis is a chronic systemic inflammatory disease. Inflammation and high levels of serum amyloid A (SAA) protein are predisposing factors for secondary AA amyloidosis. The role of SAA1 gene polymorphisms in AS is not well understood.

Objectives: To investigate the association of SAA1 gene polymorphism -13T/C (rs12218) with ankylosing spondylitis and to evaluate the influence of this polymorphism on SAA protein concentration.

Methods: 123 AS patients (72 males, 51 females; age - M (SD) 37.51 (12.77) years; disease duration - 14.28 (11.22) years; BASDAI - 5.59 (1.13); B27-positive $111(90.2 \%)$ pts) and 95 gender, age matched healthy individuals (control group) were included in this study. SAA1 gene polymorphism -13T/C was genotyped using allele-specific RT-PCR assay. SAA protein concentration was measured using nephelometry in AS patients.

Results: The distribution of genotypes TT, TC and CC differed statistically between AS and control groups (24.4\%, 56.1\%, 19.5\% and $41.1 \%, 44.2 \%, 14.7 \%$ respectively, $\chi^{2}=6.9, p=0.03$ )

The presence of the $C$ allele was associated with the development of $A S$ (OR=1.55 [Cl 1.04-2.33], $\mathrm{p}=0.03)$. The SAA1 $-13 \mathrm{~T} / \mathrm{C}$ polymorphism tended to be associated with SAA protein value in AS patients: TT+TC genotypes $-13.8 \mathrm{mg} / \mathrm{l}$ [4.2; 91.0], CC genotype $-7.8 \mathrm{mg} / \mathrm{l}[1.6 ; 29.6], \mathrm{p}=0.07$. ESR, CRP and BASDAl values did not correlated with $S A A 1-13 T / C$ polymorphism ( $p=0.6, p=0.4, p=0.4$ respectively). Conclusion: The results of our study demonstrated for the first time that SAA1 gene polymorphism -13T/C (rs12218) is associated with susceptibility to AS. It is also shown that this polymorphism can affect the SAA protein level. Our findings need to be verified in AS patients with high levels of SAA protein in various ethnic and population groups.

Disclosure of Interests: None declared

DOI: 10.1136/annrheumdis-2021-eular.2998

\section{AB0011 EXPRESSION PROFILE AND POTENTIAL FUNCTION OF CIRCRNAS IN PERIPHERAL BLOOD MONONUCLEAR CELLS FROM PATIENTS WITH PRIMARY GOUT}

Y. F. Qing ${ }^{1}$, F. Dai ${ }^{1}$, Q. B. Zhang ${ }^{2}$, Y. P. Tang ${ }^{1}$, Z. R. Dong ${ }^{1}$, Y. X. He ${ }^{1}$, Y. Jiang ${ }^{1}$, Y. Q. Huang ${ }^{2}$, J. Zheng ${ }^{1} .{ }^{1}$ Institute of Rheumatology and Immunology, Affiliated Hospital of North Sichuan Medical College, Department of Rheumatology and Immunology, Affiliated Hospital of North Sichuan Medical College, Nanchong, China; ${ }^{2}$ Institute of Rheumatology and Immunology, Affiliated Hospital of North Sichuan Medical College, Department of Geriatrics, Affiliated Hospital of North Sichuan Medical College, Nanchong, China
Background: Autophagy is a phenomenon of "self-phagocytosis" in eukaryotic cells, which maintains cell homeostasis by transporting intracellular materials to lysosomes for degradation and recycling. In recent years, studies have shown that autophagy may be involved in the pathogenesis of rheumatoid arthritis(RA) [1], but its specific mechanism is still unclear.

Objectives: The expression levels of autophagy-related genes(ATG) unc-51-like kinase 1(ULK1), ATG13, ATG17, microtubule associated protein 1 light chain 3 (LC3), and P62 in peripheral blood mononuclear cells (PBMC) of patients with RA were detected, and their role and clinical significance in the pathogenesis of RA were explored.

Methods: Real-time fluorescent quantitative PCR was performed to detect the expression levels of ULK1, ATG13, ATG17, LC3, and P62 in PBMCs of 50 RA patients, 50 healthy controls $(\mathrm{HC})$, and 25 moderate to severe RA patients before and after treatment. Then, $\mathrm{t}$ test, $\chi 2$ test, Mann-Whitney $\mathrm{U}$ test, Pearson test were used for statistical analysis.

Results: 1.The levels of hsCRP, white blood cell(WBC), neutrophils(GR), platelet(PLT) and plateletcrit(PCT) in RA group were higher than those in $\mathrm{HC}$ group ( $P<0.05)$. Lymphocytes (LY), red blood cell(RBC), hemoglobin(HGB), hematocrit(HCT), mean corpuscular hemoglobin( $(\mathrm{MCH})$, mean red blood cell volume(MCV) and mean red blood cell hemoglobin concentration( $\mathrm{MCHC}$ ) in RA group were lower than those in $\mathrm{HC}$ group $(P<0.05)$. 2. The expressions of ULK1, ATG17, and LC3 in RA group were higher than those in HC group, while the expressions of $\mathrm{P} 62$ was lower than those in $\mathrm{HC}$ group $(\mathrm{P}<0.05)$ (Figure 1). The correlation analysis suggested that ATG17 was positively correlated with tender joint count (TJC), swollen joint count (SJC), and health assessment questionnaire (HAQ) $(P<0.05)$; ULK1 and HAQ were negatively correlated $(P<0.05)$.3. Compared with before treatment with TNFi, ATG17, HAQ, DAS-28, ESR, hsCRP, WBC, GR, PLT and $\mathrm{PCT}$ were significantly reduced after treatment $(\mathrm{P}<0.05)$; the expressions of RBC, HCT, MCV and MCH were significantly increased after treatment, $(P<0.05)$; ULK1, ATG13, LC3, P62 and other related clinical and laboratory indicators were not significantly different before and after treatment with TNFi $(P>0.05)$.
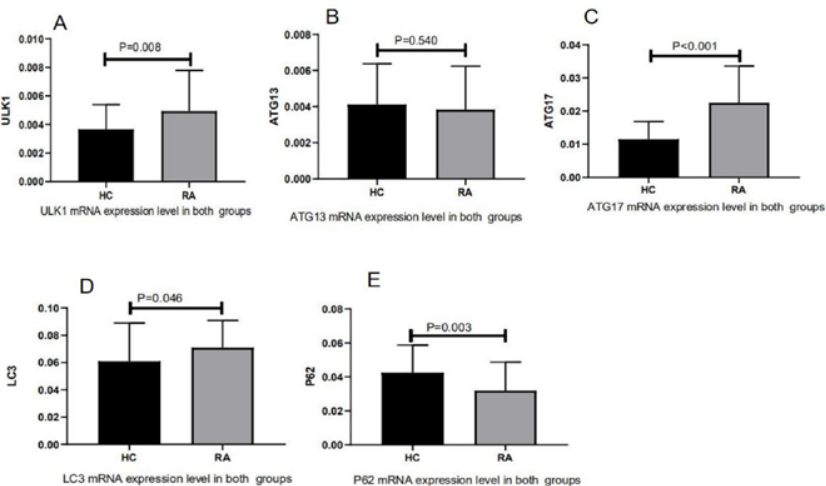

Figure 1. The expression levels of ATGs in $\mathrm{HC}$ and RA groups.

Conclusion: There is abnormal expression of autophagy genes in the periphera blood of RA patients. ULK1, ATG17, LC3 and P62 may be related to the pathogenesis of RA, among them, ATG17 may regulate the pathogenesis of RA by participating in the TNF- $\alpha$ pathway.

\section{REFERENCES:}

[1] Rockel Jason S,Kapoor Mohit,Autophagy: controlling cell fate in rheumatic diseases.[J].Nat Rev Rheumatol, 2016, 12: 517-31.

Disclosure of Interests: Yu-Feng Qing Grant/research support from: Science and Technology Project of Nanchong City (no.18SXHZ0522), Fei Dai: None declared, Quan-Bo Zhang Grant/research support from: the National Natural Science Foundation of China(General Program) (no.81974250), and Science and Technology Plan Project of Sichuan Province (no.2018JY0257), Yi-Ping Tang: None declared Zeng-Rong Dong: None declared, Yi-Xi He: None declared, Yi Jiang: None declared, Yu-Qin Huang: None declared, Jianxiong Zheng: None declared DOI: 10.1136/annrheumdis-2021-eular.3081

\section{$\mathrm{AB} 0012$}

THE EFFECTS OF COMMON THERAPEUTICS ON AIRE METHYLATION STATUS AND THE LEVELS OF IL-16, IL-1B, AND IFN- $\Gamma$ IN LPS-INDUCED MACROPHAGE CELLS CAN SULPHASALAZINE'S INFLUENCE ON METHYLATION STATUS OF AIRE EXPLAIN ITS AUTOIMMUNE SIDE EFFECTS?

Z. B. Çelik ${ }^{1}$, C. Gunaydin ${ }^{2}$, A. K. Cengiz ${ }^{3} .{ }^{1} 19$ Mayis University Medical Faculty, Medical Biology, Samsun, Turkey; ${ }^{2} 19$ Mayis University Medical Faculty, Pharmacology, Samsun, Turkey; ${ }^{3} 19$ Mayis University Medical Faculty, Physical Medicine and Rehabilitation-Rheumatology, Samsun, Turkey 